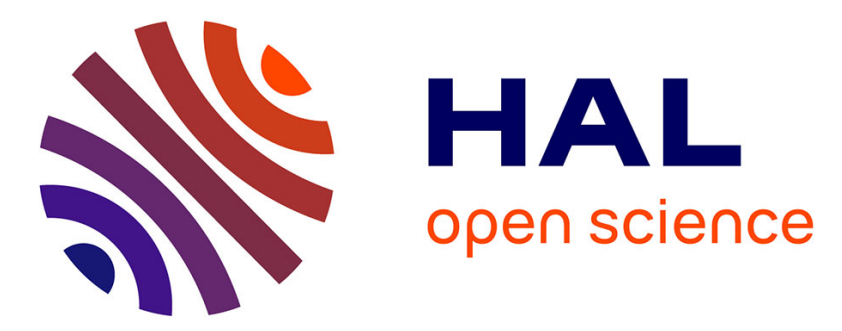

\title{
Corrosion mechanisms in aqueous solutions containing dissolved H2S. Part 2: Model of the cathodic reactions on a 316L stainless steel rotating disc electrode
} Bernard Tribollet, Jean Kittel, A. Meroufel, F. Ropital, F Grojean, Eliane Sutter, F. Grosjean

\section{To cite this version:}

Bernard Tribollet, Jean Kittel, A. Meroufel, F. Ropital, F Grojean, et al.. Corrosion mechanisms in aqueous solutions containing dissolved H2S. Part 2: Model of the cathodic reactions on a 316L stainless steel rotating disc electrode. Electrochimica Acta, 2014, 124, pp.46-51. 10.1016/j.electacta.2013.08.133 . hal-01017493v2

\section{HAL Id: hal-01017493 \\ https://hal.sorbonne-universite.fr/hal-01017493v2}

Submitted on 20 Dec 2019

HAL is a multi-disciplinary open access archive for the deposit and dissemination of scientific research documents, whether they are published or not. The documents may come from teaching and research institutions in France or abroad, or from public or private research centers.
L'archive ouverte pluridisciplinaire HAL, est destinée au dépôt et à la diffusion de documents scientifiques de niveau recherche, publiés ou non, émanant des établissements d'enseignement et de recherche français ou étrangers, des laboratoires publics ou privés. 


\title{
Corrosion mechanisms in aqueous solutions containing dissolved $\mathrm{H}_{2} \mathrm{~S}$. Part 2: Model of the cathodic reactions on a 316L rotating disc electrode.
}

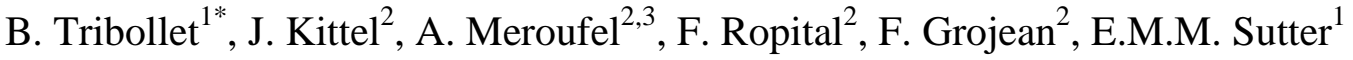 \\ ${ }^{1}$ Laboratoire Interfaces et Systèmes Electrochimiques, UPR 15 du CNRS, UPMC, 75252 Paris Cedex 05, \\ France. \\ ${ }^{2}$ IFP Energies nouvelles, Rond-point de l'échangeur de Solaize BP3, 69360 Solaize, France. \\ 3. Corrosion Department, Seawater Desalination Research Institute;Saline Water Conversion Corporation, \\ P.O. Box 8382, Al Jubail 31951 ; Kingdom of Saudi Arabia.
}

\begin{abstract}
In $\mathrm{H}_{2} \mathrm{~S}$ containing solutions, the reduction of protons with a buffer effect contributing to the transport of protons at the steel surface, is not sufficient to explain the cathodic polarization curves. An additional electrochemical reaction was observed and was attributed to a direct $\mathrm{H}_{2} \mathrm{~S}$ reduction. A numerical model is presented with these hypotheses and a good agreement is found with the experimental data presented in a previous paper. With this model it is also possible to present the concentration profiles of the different species involved in the cathodic process.
\end{abstract}

\section{Introduction}

Corrosion in weak acid solutions often represents a more complex situation than in strong acids. It is relatively well admitted that corrosion in weak acids is usually enhanced in comparison with diluted strong acids at the same $\mathrm{pH}$. A simple explanation to this fact lies in the carrier of reducible proton $\left(\mathrm{H}^{+}\right)$. In a strong acid solution, all the protons are already dissociated. Consequently, $\mathrm{pH}$ is a good indicator of the oxidizing power of the solution. On the other hand, a weak acid solution of similar $\mathrm{pH}$ still contains the same amount of $\mathrm{H}^{+}$, but also a reservoir of protons in the form of undissociated weak acid molecules. The oxidizing power is thus accounted for by both $\mathrm{pH}$ and the concentration of weak acid, with immediate consequences on the intensity of the cathodic reaction at a given potential. In acid solution, $\mathrm{H}^{+}$ reduction is often the major source of cathodic current. In a weak acid solution, this cathodic reaction is both fed by $\mathrm{H}^{+}$diffusion from the bulk, but also by the diffusion of the weak acid and its subsequent dissociation, in a so called buffer effect. The increase of cathodic current associated with this buffer effect is therefore seen as soon as a $\mathrm{H}^{+}$diffusion limitation is reached, and the higher the weak acid concentration is, the higher the increase of cathodic current. However, in order to explain the increase of cathodic current, the hypothesis of electroactivity of the weak acid is also often proposed. The direct reduction of the weak acid is then mathematically added to proton reduction, thus increasing the total cathodic current density.

Although the differences between those two mechanisms might seem subtle, major differences have to be pointed out. The buffer effect arises purely from chemical equilibria and kinetics, without potential dependence. It is therefore necessarily always a contributor. However, this contribution starts only in the potential region where $\mathrm{H}^{+}$reduction is under mass transport control: the weak acid then acts as a buffer, and is transported from the bulk to the electrode surface, where it dissociates to generate $\mathrm{H}^{+}$in situ. As a consequence, cathodic polarization curves are expected to remain unchanged in the $\mathrm{H}^{+}$charge transfer region, while 
the diffusion limited plateau must be increased with an amplitude corresponding to diffusion of the weak acid.

On the contrary, a direct reduction has a strong dependence on potential. It may or it may not be found in the potential range of $\mathrm{H}^{+}$reduction, depending on the nature of the electrode, the nature of the weak acid and its concentration. When the contribution of weak acid reduction is not negligible, it thus presents its own current - potential characteristics with charge transfer and mass transfer limited regions, which are superimposed to $\mathrm{H}^{+}$reduction, enhanced by the buffer effect which is still present. If both reduction reactions have distinct potential regions and not too dissimilar current densities, two distinct electrochemical waves should be observed in the current - potential curves.

In oil and gas environments, three major weak acids are encountered: from the strongest to the weakest, organic acids, with acetic acid $\left(\mathrm{CH}_{3} \mathrm{COOH}\right)$ as the main component, carbonic acid $\left(\mathrm{H}_{2} \mathrm{CO}_{3}\right)$ and hydrosulfuric acid $\left(\mathrm{H}_{2} \mathrm{~S}\right)$. While it is known from decades that these acids strongly enhance the corrosion rates of mild steel [1-13] the level of understanding differs widely between them. $\mathrm{CO}_{2}$ corrosion has probably benefited the widest and earliest investigations, and it is known from long that the increase of corrosion rate is associated with an increase of cathodic current density [4,5,7,9-12]. While direct reduction of $\mathrm{H}_{2} \mathrm{CO}_{3}$ remained the most often cited mechanism until the late 2000's, a recent consensus seems adopted on the buffer effect which was first proposed in 1974 [12]. This mechanism was recently confirmed by a reactive transport model showing that no additional reduction reaction was necessary to describe cathodic reactions in $\mathrm{CO}_{2}$ solutions [14]. Similarly, recent studies on acetic acid corrosion also showed that a direct reduction was not likely [15], also confirming older thoughts [3].

On the other hand, studies on $\mathrm{H}_{2} \mathrm{~S}$ corrosion were mainly focused on anodic mechanism or on the formation of $\mathrm{FeS}$ scale formation [8,16-19]. Electrochemical aspects of $\mathrm{H}_{2} \mathrm{~S}$ benefited much less investigations, though it was found to have strong impact on the cathodic current density $[1,8,20]$. Recent electrochemical investigations were thus performed using well controlled hydrodynamic systems and show that $\mathrm{H}_{2} \mathrm{~S}$ contribution might not fully be explained by a buffer effect $[21,22]$.

In Part 1 of this paper, an electrochemical model for the cathodic reactions in $\mathrm{H}_{2} \mathrm{~S}$ solutions was proposed [21]. A buffer behaviour similar to $\mathrm{CO}_{2}$ was first considered, where $\mathrm{H}_{2} \mathrm{~S}$ contributes through its dissociation reactions as an additional source of protons at the corroding surface:

$$
\begin{aligned}
& \mathrm{H}_{2} \mathrm{~S} \leftrightarrow \mathrm{H}^{+}+\mathrm{HS}^{-} \\
& \mathrm{HS}^{-} \leftrightarrow \mathrm{H}^{+}+\mathrm{S}^{2-}
\end{aligned}
$$

As in the case of $\mathrm{CO}_{2}$ [23], it is not postulated that these reactions always stand at thermodynamic equilibrium. It could thus be necessary to consider the chemical kinetics expressions:

$$
\begin{aligned}
& R_{1}=k_{1} C_{H_{2} S}-k_{-1} C_{H S^{-}} C_{H^{+}} \\
& R_{2}=k_{2} C_{H S^{-}}-k_{-2} C_{S^{2-}} C_{H^{+}}
\end{aligned}
$$

where $R_{1}, k_{1}$ and $k_{-1}$ are respectively the rates of the reaction and the forward and backward kinetic constants for $\mathrm{H}_{2} \mathrm{~S}$ dissociation (Reaction (1)), and where $R_{2}, k_{2}$ and $k_{-2}$ have the same meaning for $\mathrm{HS}^{-}$dissociation (Reaction (2)). Although the kinetic rate constants for these 
reactions are not well documented in the literature, it is often postulated that the dissociation of $\mathrm{H}_{2} \mathrm{~S}$ is much faster than for $\mathrm{CO}_{2}$ [24].

As it was also shown in [21], the buffer effect is not sufficient to explain the experimental cathodic curves: an additional electrochemical reaction was observed at higher cathodic potential, which could not be represented by the proton reduction after weak acid transport and dissociation. The hypothesis of a direct reduction reaction was then considered as proposed by Bolmer [1]:

$$
\mathrm{H}_{2} \mathrm{~S}+\mathrm{e}^{-} \leftrightarrow \mathrm{HS}^{-}+\frac{1}{2} \mathrm{H}_{2}
$$

The reaction order of this last reaction was experimentally determined in [21] and a value of 0.5 was found as for the proton.

Finally the expression of the current density for the reaction (3) was obtained after the determination of the Tafel slope:

$$
J_{\mathrm{H}_{2} S}=k_{\mathrm{H}_{2} S} C_{\mathrm{H}_{2} \mathrm{~S}}^{0.5}(\mathrm{O}) 10^{\frac{-E}{b_{c, H_{2} S}}}
$$

where $k_{\mathrm{H}_{2} \mathrm{~S}}$ is the cathodic rate constant of $\mathrm{H}_{2} \mathrm{~S}$ reduction, $C_{\mathrm{H}_{2} \mathrm{~S}}(\mathrm{O})$ is the $\mathrm{H}_{2} \mathrm{~S}$ concentration at the electrode surface, $E$ is the electrode potential, and $b_{c, H_{2} S}$ is the cathodic Tafel slope equal to $145 \pm 10 \mathrm{mV}(1)$.

\section{Governing equations}

Generally, the solution under investiagation contains different ions as $\mathrm{Na}^{+}, \mathrm{SO}^{--}, \mathrm{Cl}^{-}$and then in this approach the migration is neglected. The migration can play a significant role only in pure water which is not realistic in oil and gas industry.

The governing equations of the system are the mass balance equations expressed for each species $i$ of the model. These equations can be written according to:

$$
-D_{i} \frac{\partial^{2} C_{i}}{\partial x^{2}}+V_{x} \frac{\partial C_{i}}{\partial x}=R_{i}
$$

with Di the diffusion coefficient of species $i, C_{i}$ its concentration, $V_{x}$ the convective transport rate in the direction normal to the electrode surface, and $R_{i}$ the homogeneous production rate, determined from (3) and (4) with the following relations:

$$
\begin{aligned}
& R_{H^{+}}=R_{1}+R_{2} \\
& R_{H_{2} S}=-R_{1} \\
& R_{H S^{-}}=R_{1}-R_{2} \\
& R_{S^{2-}}=-R_{2}
\end{aligned}
$$

According to Levich [25], the convective term for a rotating disc electrode can be expressed as:

$$
V_{x}=-0.51 v^{-1 / 2} \omega^{3 / 2} x^{2}
$$


Where $v$ is the kinematic viscosity of the solution, $\omega$ is the angular rotation speed of the electrode, and $x$ is the normal distance to the electrode surface.

The complete system is described by a set of four coupled non linear differential equations (7), to solve it, the boundary conditions at the interface and in the bulk of the solution must be defined.

\subsection{Boundary conditions in the bulk of the solution:}

Far from the electrode, it is reasonable to consider that thermodynamic equilibrium is reached. Thus for a given $\mathrm{pH}$ and a given partial pressure of $\mathrm{H}_{2} \mathrm{~S}\left(\mathrm{P}_{\mathrm{H}_{2} \mathrm{~S}}\right)$, the bulk concentration can easily be calculated as:

$$
\begin{aligned}
& C_{\mathrm{H}_{2} S}=H_{\mathrm{H}_{2} S} P_{\mathrm{H}_{2} S} \\
& C_{\mathrm{HS}^{-}}=K_{1} \frac{C_{\mathrm{H}_{2} S}}{C_{H^{+}}} \\
& C_{S^{2-}}=K_{2} \frac{C_{H S^{-}}}{C_{H^{+}}}
\end{aligned}
$$

where $H_{H_{2} S}$ is the Henry's constant for $\mathrm{H}_{2} \mathrm{~S}$, and $K_{1}$ and $K_{2}$ are respectively the equilibrium constant of Reaction (1) and Reaction (2).

It appears that $C_{S^{2-}}=K_{1} \cdot K_{2} \frac{C_{H_{2} S} \cdot C_{H S^{-}}}{C_{H^{+}}^{2}}$ and the corresponding value is very small, then for the $\mathrm{pH}$ value under investigation $\left(\mathrm{pH}=4\right.$ and $\mathrm{pH}=6$, the concentration in $\mathrm{S}^{2-}$ is negligible and the homogeneous reaction (2) can be ignored in the present work.

2.2 Boundary conditions at the electrode surface:

At the electrode surface the flux of non electroactive species is necessarily equal to zero:

$$
\left.\frac{\partial C_{H S^{-}}}{\partial x}\right|_{x=0}=\left.\frac{\partial C_{S^{2-}}}{\partial x}\right|_{x=0}=0
$$

The electroactive species are $\mathrm{H}^{+}$and $\mathrm{H}_{2} \mathrm{~S}$, then:

$$
\begin{aligned}
& \left.D_{H_{2} S} \frac{\partial C_{H_{2} S}}{\partial x}\right|_{x=0}=J_{H_{2} S} \\
& \left.D_{H^{+}} \frac{\partial C_{H^{+}}}{\partial x}\right|_{x=0}=J_{H^{+}}
\end{aligned}
$$

$J_{H_{2} S}$ is given by the expression (6) and the expression for $J_{H^{+}}$is similar and given in [21]. The boundary conditions (17) and (18) linked the concentration at the electrode to the concentration gradient. 


\section{$3 \quad$ Numerical solutions}

\subsection{Current-potential curves}

Due to the product of concentrations $C_{H S} C_{H^{+}}$in equation (3) the system is non linear. Only the equilibrium constant $K_{1}$ is tabulated but $k_{1}$ is unknown and can be determined by comparison between the numerical derivation and the experimental data. The corresponding values $k_{-1}$ is deduced from the values of $k_{1}\left(k_{-1}=K_{1} / k_{1}\right)$.

The numerical value for the overall current is:

$$
i=F\left(J_{H_{2} S}+J_{H^{+}}\right)
$$

The dissociation of $\mathrm{HS}^{-}$is neglected, the system is then reduced to three differential equations with three unknowns and only $k_{l}$ must be determined.

The stationary cathodic polarization curves measured with a rotating disc electrode at $\mathrm{pH} 4 \mathrm{in}$ $\mathrm{H}_{2} \mathrm{~S}$ saturated (9 mbar) solution is recalled in Figure 1 at $600 \mathrm{rpm}$. Two waves can be clearly seen and are attributed to the reduction of the proton and to the reduction of $\mathrm{H}_{2} \mathrm{~S}$ (reaction (5)). For potentials more cathodic than $-1 \mathrm{~V}$, a third wave can be observed corresponding to the water reduction and is not considered in the present simulation.

The parameters corresponding to the simulation presented in Figure 1 are given in Table 1. The results of the derivation are also given in Figure 1, a good agreement between the experimental data and the simulation is obtained. The wave corresponding to the $\mathrm{H}_{2} \mathrm{~S}$ reduction is obtained by taking a value for $k_{\mathrm{H}_{2} \mathrm{~S}}$ lower than the value of $k_{H^{+}}$(see Table 1).

In order to characterize in more details the electrochemical reactions associated with $\mathrm{H}_{2} \mathrm{~S}$, additional experiments were performed in [21] with different $P_{\mathrm{H}_{2} \mathrm{~S}}$ or less acidic solutions. All simulations are obtained with the same set of coefficients (Table 1).

At $\mathrm{pH} 4$ for 9 and $50 \mathrm{mbar}$ of $\mathrm{H}_{2} \mathrm{~S}$, the additional contribution to the proton reduction appears on the polarization curves of Figure 2. For 1 mbar only the reduction of the proton appears clearly. As in Figure 1 the agreement between the simulated curves and the experimental data is satisfactory.

At $\mathrm{pH} 6$ for the different concentrations in $\mathrm{H}_{2} \mathrm{~S}$, the cathodic contribution of the polarization curves can be attributed to $\mathrm{H}_{2} \mathrm{~S}$ and to the water reduction. The simulation confirms that the limiting plateau is proportional to the $\mathrm{H}_{2} \mathrm{~S}$ concentration, but the water reduction is not introduced in the model (Figure 3).

The stationary cathodic polarization curves in the limiting current domain are plotted in Figure 4 for different rotation rates of the electrode at $\mathrm{pH} 6$ and with $50 \mathrm{mbar}_{2} \mathrm{H}_{2} \mathrm{~S}$. The simulated curves show a good agreement for the kinetic part but a clear discrepancy in the limiting current region. Only the curve at $180 \mathrm{rpm}$ is in agreement with the experimental data.

The limiting cathodic current is plotted versus the square root of the rotation speed in Figure 5. On this figure the simulated points corresponding to the previous curves are reported with a black square, and correspond to a $k_{1}$ value of 0.2 . The simulated points are below the Levich plot and the corresponding curve is parallel to the Levich curve. To see the effect of $\mathrm{k}_{1}$ on the simulated results, for the same conditions the current was simulated with a $\mathrm{k}_{1}$ value of 0.5 . Again the corresponding curve is below the Levich curve but always parallel to the Levich curve. The experimental data follow a completely different behaviour, the increase of the current with the rotation speed is much lower than the square root of the rotation speed. To understand the effect of $k_{1}$ on the limiting current, in Figure 6 the limiting current corresponding to a rotation speed of $180 \mathrm{rpm}$ for a solution at $\mathrm{pH} 6$ and with $50 \mathrm{mbar}_{2} \mathrm{~S}$ is 
plotted versus the $k_{l}$ value. Clearly the value of $k_{l}$ plays an important role for $k_{1}$ around 0.1 and in order to obtain the best agreement on Figure 1 a value of 0.2 was chosen. The homogeneous reaction (1) influences the limiting current if the $k_{l}$ value is larger than 0.01 . For $k_{1}$ value below 0.01 the current follows the Levich law and the homogeneous reaction plays no role on the limiting current value.

\subsection{Concentration profiles}

The previous model needs to derive the concentration field near the electrode for each species involved in the reaction. An example of the concentration variation versus the normal distance of the electrode is given in Figure 7. The distance is dimensionless by using the diffusion layer thickness corresponding to the proton. In Figure 7 it appears clearly than in mixed kinetic for $\mathrm{H}_{2} \mathrm{~S}$ (potential $=-0.83 \mathrm{~V}$ ) the concentration at the interface is not zero but at this potential the reduction of $\mathrm{H}^{+}$is mass transport limited and the concentration at the interface is zero. It appears also that the concentration gradient of $\mathrm{HS}^{-}$at the interface is equal to zero in agreement with the boundary conditions.

In Figure 8, the concentration profiles are presented for a potential corresponding to the limiting current of $\mathrm{H}_{2} \mathrm{~S}$. In the coordinates used in this figure, the difference between the thickness of the diffusion layer for the proton and for $\mathrm{H}_{2} \mathrm{~S}$ appears clearly; this difference is obviously due to the difference between the diffusion coefficients of the two species. The $\mathrm{HS}^{-}$ concentration is too small in this representation to be visible on this figure.

Finally, the effect of the forward constant $k_{1}$ on the concentration profile of $\mathrm{H}_{2} \mathrm{~S}$ is represented in Figure 9. In agreement with figure 6, the concentration profile for a $k_{1}$ value small enough tends towards the concentration profile without any homogeneous reaction, and for higher values of $k_{l}$ the concentration gradient at the interface decreases. It is interesting to notice that the $\mathrm{H}_{2} \mathrm{~S}$ concentration reaches the bulk concentration at distance 6 or 7 times larger for $k_{1}$ equal 0.5 than for $k_{1}$ equal 0.001 . As consequence for large value of $k_{1}$ the numerical integration of the mass balance equation must be performed on a larger distance.

\section{Discussion}

As shown experimentally in part 1 of this paper [21], and also observed in [22], the hydrogen evolution in an oxygen free solution with dissolved $\mathrm{H}_{2} \mathrm{~S}$ is different from that observed with dissolved $\mathrm{CO}_{2}$, even though both dissolved gasses are weak acids with comparable solubility and $\mathrm{pKa}$. In the $\mathrm{pH}$ region of interest for oil and gas environments, typically between 4 and 6 , the concentration of dissolved acid gases $\left(\mathrm{CO}_{2}\right.$ and $\left.\mathrm{H}_{2} \mathrm{~S}\right)$ is usually several orders of magnitude higher than the concentration of proton. Electrochemical reactions at the steel surface are then under strong influence of the transport of the weak acids coupled with their dissociation. However, while this reactive transport scheme with proton reduction as unique cathodic contribution was sufficient to describe polarisation curves in carbonic acid solutions, the same model could not be applied satisfactorily with $\mathrm{H}_{2} \mathrm{~S}$. As shown by numerical results presented in this paper, the buffer effect is not sufficient to explain cathodic polarization curves measured in solutions with dissolved $\mathrm{H}_{2} \mathrm{~S}$. The hypothesis of an additional reduction of $\mathrm{H}_{2} \mathrm{~S}$ was considered and the numerical curves are in good agreement with the experimental ones. However a discrepancy appears for the variation of the limiting current with the rotation speed, in contradiction with experimental results of [22], obtained with mild steel electrode. Several hypothesis might be proposed to explain this discrepancy. Sulfide adsorbates at the electrode surface might have disturbed the system, inducing areas with distinct electrochemical reactivities. Thus, the additional electrochemical wave might be linked with a second $" \mathrm{H}_{2} \mathrm{~S}$ modified surface" rather than with, or in addition to, a second electroactive 
species. This reaction scheme is also in good agreement with the current understanding of the impact of $\mathrm{H}_{2} \mathrm{~S}$ on hydrogen charging in steel, considering proton reduction through $\mathrm{HS}^{-}$ adsorbate [26].

Another type of surface disturbance might also explain the experimental variation of the limiting current with the rotation speed. This difference could be due to the fact that the direct corrosion of iron with $\mathrm{H}_{2} \mathrm{~S}$ and the formation of a corrosion deposit were not taken into account in the present model [18].

Although it is not possible to conclude at this stage, it seems also that these hypotheses strongly depend on the electrode material. While we used stainless steel for its relative inertness for this investigation, carbon steel presents a much greater practical interest, and constitutes the main perspective to this work. In particular, the rapid formation of corrosion scales is expected, constituting a porous diffusion layer. The model could then be modified in order to remove the convective transport contributions, and apply a diffusion layer in the typical range of corrosion scales, from tens of micrometres to millimetres. This will also require taking account of ferrous ions diffusions from the steel surface through the porous layer, and also consider precipitation reactions. This model could then be applied to discuss corrosion under deposit mechanisms as described in [27,28]. Such mechanistic models of $\mathrm{CO}_{2}$ and $\mathrm{H}_{2} \mathrm{~S}$ underdeposit corrosion already exist, but they do not incorporate actual understanding of $\mathrm{H}_{2} \mathrm{~S}$ electrochemistry and reactive transport [19].

Improving the understanding of $\mathrm{H}_{2} \mathrm{~S}$ corrosion of carbon steel would also be valuable for hydrogen cracking applications, with a better understanding of the impact of adsorbates on hydrogen entry.

\section{$5 \quad$ Conclusion}

The contribution of $\mathrm{H}_{2} \mathrm{~S}$ to cathodic reactions differs from that of $\mathrm{CO}_{2}$ or acetic acid. In the latter case, proton reduction is the main cathodic reaction, and dissolved $\mathrm{CO}_{2}$ or acetic acid only contribute to increase the current density in the mass transfer control potential range by a chemical buffer effect. While such buffer effect still holds with $\mathrm{H}_{2} \mathrm{~S}$, it is no more sufficient to explain the rise of cathodic current, and the appearance of a second electrochemical wave. A kinetic model, including both a buffer effect and a direct $\mathrm{H}_{2} \mathrm{~S}$ reduction was proposed in Part 1 of this paper. Numerical resolution was proposed in this paper, and showed good agreement with experimental data obtained on a 316 L rotating disc electrode in $\mathrm{pH}$ region 4 to 6 and $\mathrm{H}_{2} \mathrm{~S}$ partial pressure from 1 to 50 mbar.

\section{References}

[1] P.W. Bolmer, Polarization of iron in $\mathrm{H}_{2} \mathrm{~S}-\mathrm{NaHS}$ buffers, Corrosion 21 (1965) 69-75.

[2] J.L. Crolet, Acid corrosion in wells $\left(\mathrm{CO}_{2}, \mathrm{H}_{2} \mathrm{~S}\right)$ : Metallurgical aspects, International Petroleum Exhibition and Technical Symposium of the Society of Petroleum Engineers (SPE10045), Bejing, China, 18-26 March (1982).

[3] J.L. Crolet and M.R. Bonis, The role of acetate ions in $\mathrm{CO}_{2}$ corrosion, NACE Corrosion/83 paper $n^{\circ} 160$, Anaheim, CA (USA) 18-22 April (1983).

[4] C. Dewaard and D.E. Milliams, Carbonic-Acid Corrosion of Steel, Corrosion 31 (1975) 177-181.

[5] L.G.S. Gray, B.G. Anderson, M.J. Danysh, and P.R. Tremaine, Mechanisms of carbon steel corrosion in brines containing dissolved carbon dioxide at $\mathrm{pH} 4$, NACE Corrosion/89 paper $n^{\circ} 464$, New Orleans, LO (USA) 17-21 April (1989). 
[6] K.L.J. Lee and S. Nesic, The effect of trace amount of $\mathrm{H}_{2} \mathrm{~S}$ on $\mathrm{CO}_{2}$ corrosion investigated by using EIS technique, NACE Corrosion/2005 paper $\mathrm{n}^{\circ} 630$, Houston, TX (USA) 3-7 April (2005).

[7] B.R. Linter and G.T. Burstein, Reactions of pipeline steels in carbon dioxide solutions, Corrosion Science 41 (1999) 117-139.

[8] D.R. Morris, L.P. Samplaleanu, and D.N. Veysey, The corrosion of steel by aqueous solutions of hydrogen sulfide, Journal of the Electrochemical Society 127 (1980) 1223-1235.

[9] S. Nesic, N. Thevenot, J.L. Crolet, and D.M. Drazic, Electrochemical properties of iron dissolution in the presence of CO2 - Basics revisited, NACE Corrosion/96 paper $n^{\circ} 3$ Denver, CO (USA) 24-29 March (1996).

[10] G. Schmitt and B. Rothman, Studies of the corrosion mechanism of unalloyed steels in oxygen-free carbon dioxide solutions. Part I. Kinetics of the liberation of hydrogen,

Werkstoffe und Korrosion 28 (1977) 816-822.

[11] G. Schmitt, Fundamental aspects of $\mathrm{CO}_{2}$ corrosion, NACE Corrosion/83 paper $\mathrm{n}^{\circ} 43$, Anaheim, CA (USA) 18-22 April (1983)..

[12] W. Schwenk, Corrosion of unalloyed steel in oxygen-free carbonic acid solutions, Werkstoffe und Korrosion 25 (1974) 643.

[13] S.N. Smith and M.W. Joosten, Corrosion of carbon steel by $\mathrm{H}_{2} \mathrm{~S}$ in $\mathrm{CO}_{2}$ containing oilfield environments, NACE Corrosion/2006 paper $n^{\circ} 115$, San Diego, CA (USA) 12-16 March (2006).

[14] E. Remita, B. Tribollet, E. Sutter, V. Vivier, F. Ropital, and J. Kittel, Hydrogen evolution in aqueous solutions containing dissolved $\mathrm{CO}_{2}$ : Quantitative contribution of the buffering effect, Corrosion Science 50 (2008) 1433-1440.

[15] T. Tran, B. Brown, S. Nesic, and B. Tribollet, Investigation of the mechanism for acetic acid corrosion of mild steel, Corrosion/2013 paper $n^{\circ} 2487$, Orlando, FL (USA) 17-21 March (2013).

[16] Z.A. Iofa, V.V. Batrakov, and Cho-Ngok-Ba, Influence of anion adsorption on the action of inhibitors on the acid corrosion of iron and cobalt, Electrochimica Acta 9 (1964) 1645-1653.

[17] B. Le Boucher, Catalytic action of $\mathrm{HS}^{-}$chemisorbed ions on iron in corrosion processes, $4^{\text {th }}$ International Congress on Metallic Corrosion 550-555, Amsterdam (The Netherlands) (1972)

[18] D.W. Shoesmith, P. Taylor, M.G. Bailey, and D.G. Owen, The Formation of ferrous monosulfide polymorphs during the corrosion of iron by aqueous hydrogen-sulfide at 21Degrees-C, Journal of the Electrochemical Society 127 (1980) 1007-1015.

[19] W. Sun and S. Nesic, A mechanistic model of uniform hydrogen sulfide/carbon dioxide corrosion of mild steel, Corrosion 65 (2009) 291-307.

[20] R. Galvan-Martinez, J. Mendoza-Flores, R. Duran-Romero, and J. Genesca, Effect of turbulent flow on the anodic and cathodic kinetics of API X52 steel corrosion in $\mathrm{H}_{2} \mathrm{~S}$ containing solutions. A rotating cylinder electrode study, Materials and Corrosion 58 (2007) 514-521.

[21] J. Kittel, F. Ropital, F. Grosjean, E.M.M. Sutter, and B. Tribollet, Corrosion mechanisms in aqueous solutions containing dissolved $\mathrm{H}_{2} \mathrm{~S}$. Part 1: Characterisation of $\mathrm{H}_{2} \mathrm{~S}$ reduction on a 316L rotating disc electrode, Corrosion Science 66 (2013) 324-329.

[22] Y. Zheng, B. Brown, and S. Nesic, Electrochemical study and modeling of $\mathrm{H}_{2} \mathrm{~S}$ corrosion of mild steel, NACE Corrosion/2013 paper $n^{\circ} 2406$, Orlando, FL (USA) 17-21 March (2013).

[23] E. Remita, B. Tribollet, E. Sutter, F. Ropital, X. Longaygue, J. Kittel, C. Taravel-Condat, and N. Desamais, A kinetic model for $\mathrm{CO}_{2}$ corrosion of steel in confined aqueous environments, Journal of the Electrochemical Society 155 (2008) C41-C45. 
[24] M. Nordsveen, S. Nesic, R. Nyborg, and A. Stangeland, A mechanistic model for carbon dioxide corrosion of mild steel in the presence of protective iron carbonate films - Part 1: Theory and verification, Corrosion 59 (2003) 443-456.

[25] V.G. Levich, Physicochemical Hydrodynamics, Prentice Hall, Englewood Cliffs, New Jersey (1962).

[26] J.L. Crolet and M.R. Bonis, Revisiting hydrogen in steel, part I: theoretical aspects of charging, stress cracking and permeation, NACE Corrosion/2001 paper $n^{\circ} 67$, Houston, TX (USA) 11-16 March (2001).

[27] J.L. Crolet, Mechanisms of uniform corrosion under corrosion deposits, Journal of Materials Science 28 (1993) 2589-2606.

[28] J.L. Crolet, The electrochemistry of corrosion beneath corrosion deposits, Journal of Materials Science 28 (1993) 2577-2588. 


\section{Figure captions}

Fig 1 : Stationary cathodic polarization curves measured with a $\mathrm{RDE}$ at pH4 in 9 mbar $\mathrm{H}_{2} \mathrm{~S}$ saturated solution for a rotation speed of $600 \mathrm{rpm}$. The simulated points are obtained by solving the set of three differential equations (7).

Fig 2 : Stationary cathodic polarization curves measured with a RDE at $180 \mathrm{rpm}$ in deaerated solution containing different amount of $\mathrm{H}_{2} \mathrm{~S}$ at $\mathrm{pH}$ 4. The simulated points are obtained by solving the set of three differential equations (7).

Fig 3: Stationary cathodic polarization curves measured with a RDE at $180 \mathrm{rpm}$ in deaerated solution containing different amount of $\mathrm{H}_{2} \mathrm{~S}$ at $\mathrm{pH}$ 6. The simulated points are obtained by solving the set of three differential equations (7).

Fig 4: Experimental stationary cathodic polarization curves measured with a RDE at different

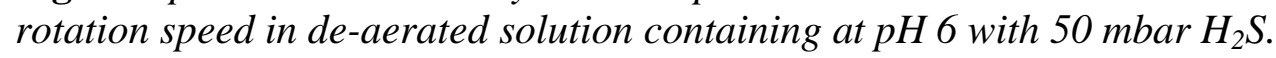

Fig 5: Evolution of the limiting cathodic current with the rotation speed of the electrode in de-

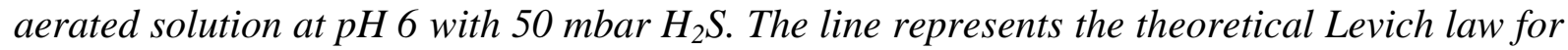
$H_{2} \mathrm{~S}$ and the different square the simulated points with different values of the parameter $k_{1}$.

Fig 6: Variation of the limiting current in function of the $k_{1}$ value for a solution at $\mathrm{pH} 6$ with $50 \mathrm{mbar}_{2} \mathrm{~S}$ and a rotation speed of $180 \mathrm{rpm}$.

Fig 7: Concentration profiles for the three species in mixed kinetic $(E=-0.83, p H=4, \Omega=$ $180 \mathrm{rpm}, P_{\mathrm{H}_{2} \mathrm{~S}}=9 \mathrm{mbar}$ )

Fig 8: Concentration profiles according to the normal dimensionless distance to the electrode for a potential corresponding to the limiting current plateau of $\mathrm{H}_{2} \mathrm{~S} .(\mathrm{pH}=4, \Omega=1200 \mathrm{rpm}$, $P_{\mathrm{H}_{2} \mathrm{~S}}=1$ mbar)

Fig 9: Concentration profiles of $\mathrm{H}_{2} \mathrm{~S}$ for different $k_{1}$ values. $\left(\mathrm{pH}=6, \Omega=180 \mathrm{rpm}, P_{\mathrm{H}_{2} \mathrm{~S}}=50\right.$ mbar) 


\section{Table caption}

Table 1: Values of the constant used for the calculation $\left(T=25^{\circ} \mathrm{C}\right)$. Remark the difference between the value of $k_{H^{+}}$given in this table and in [1] is due to the difference of reference electrode used in [1] (SSE and in the present work $(\mathrm{Ag} / \mathrm{AgCl})$. 


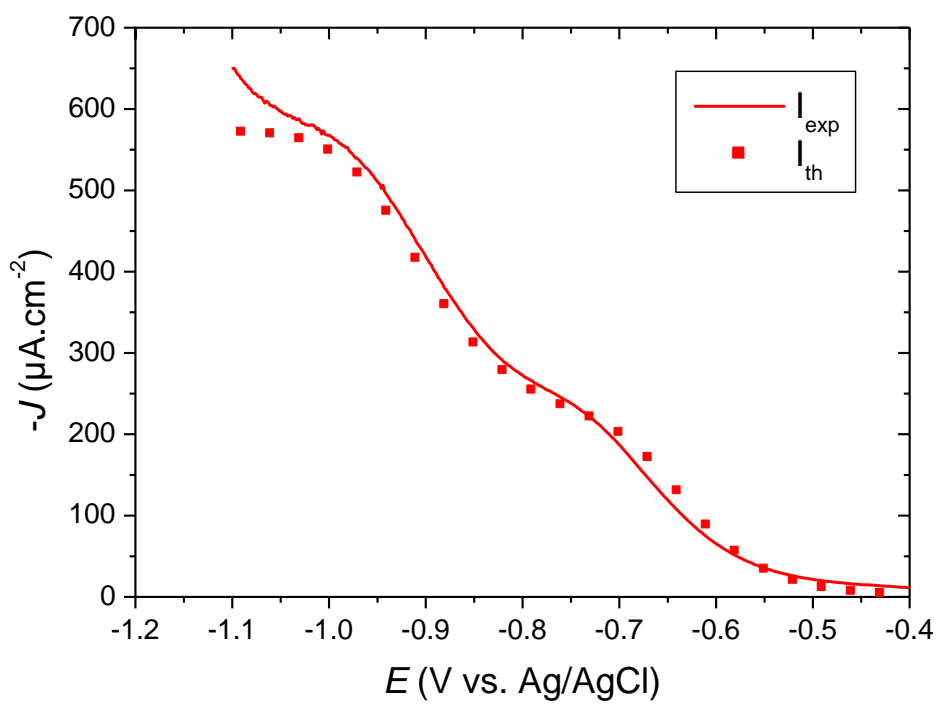

Figure 1 


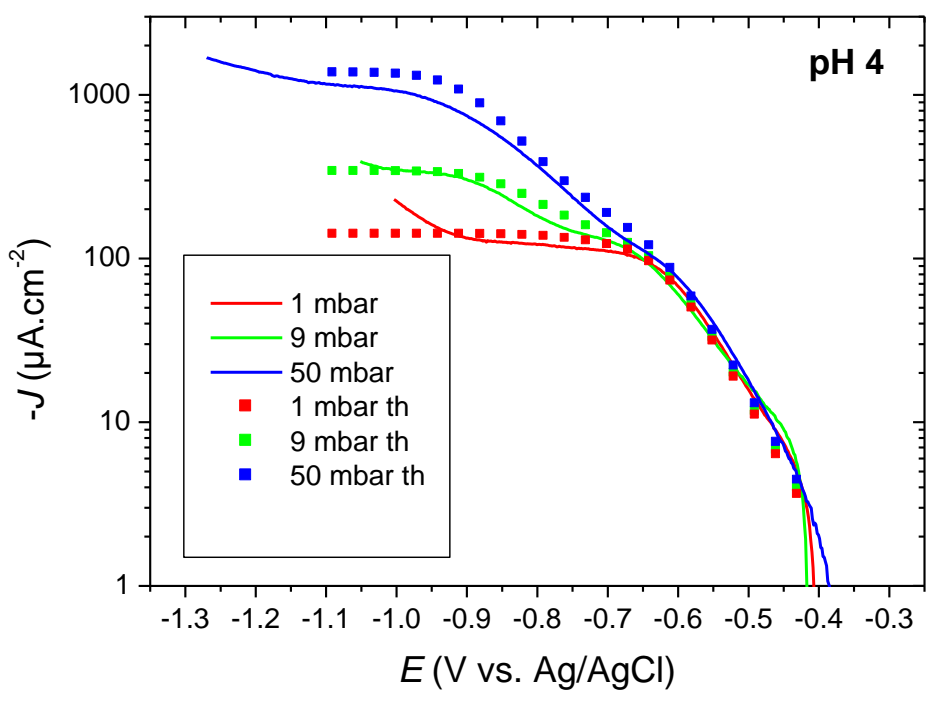

Figure 2 


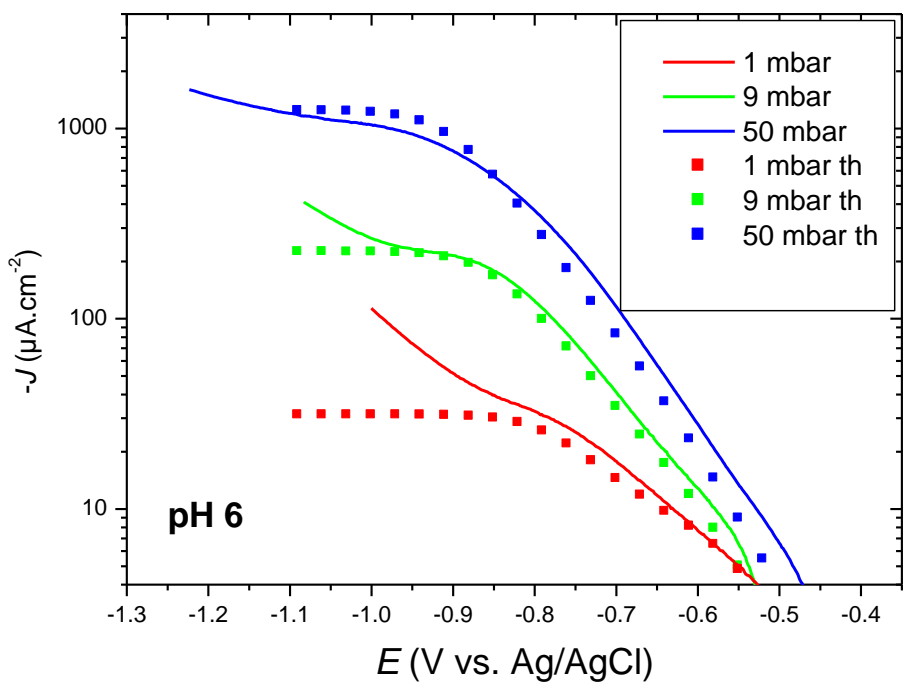

Figure 3 


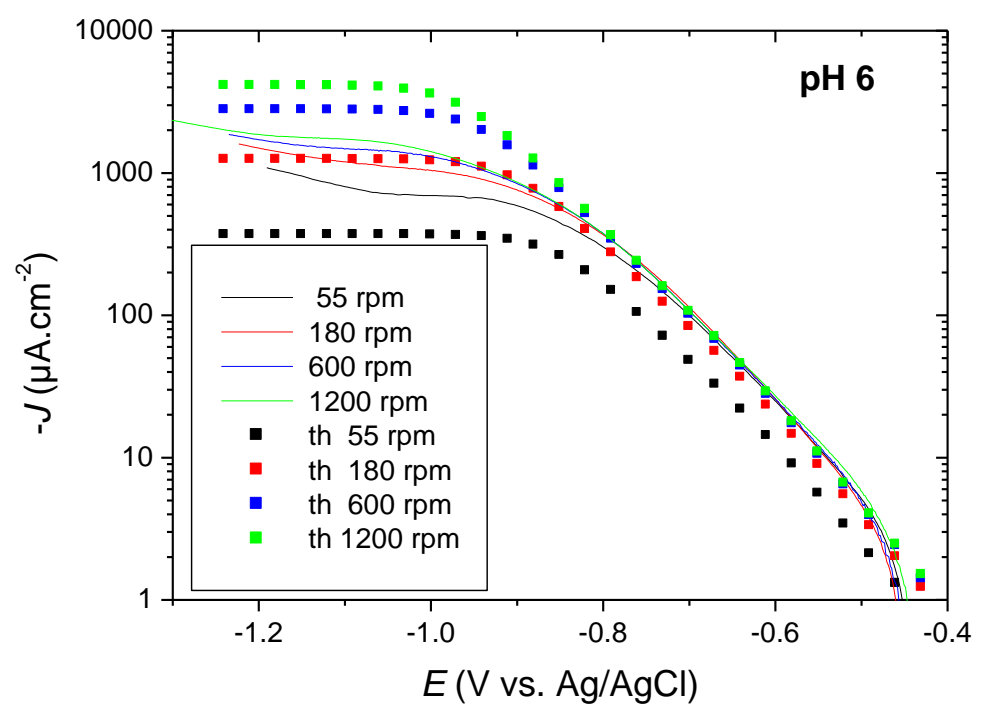

Figure 4 


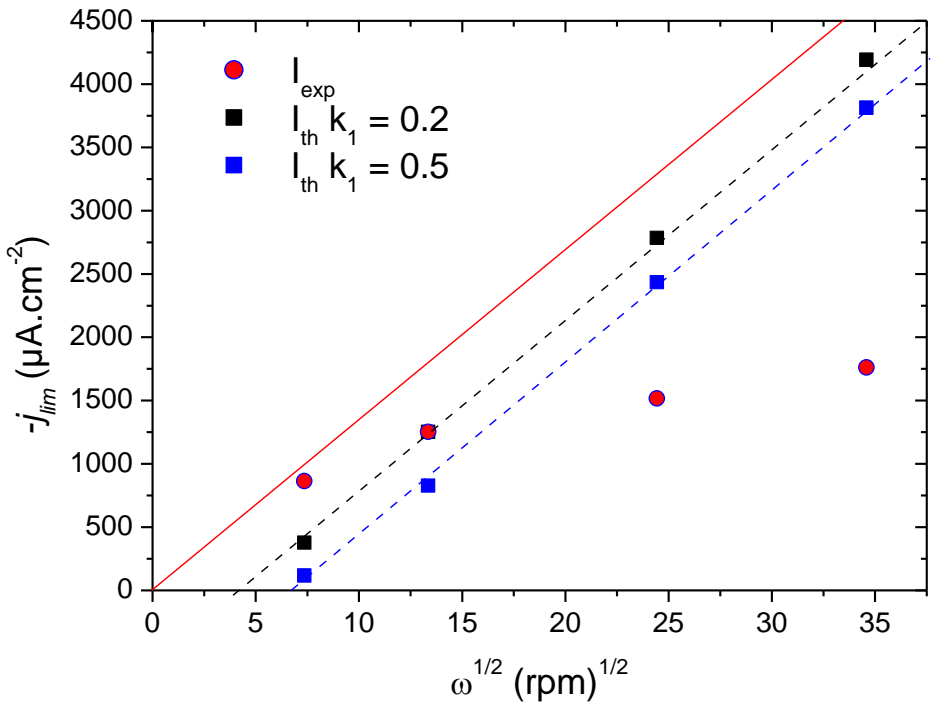

Figure 5 


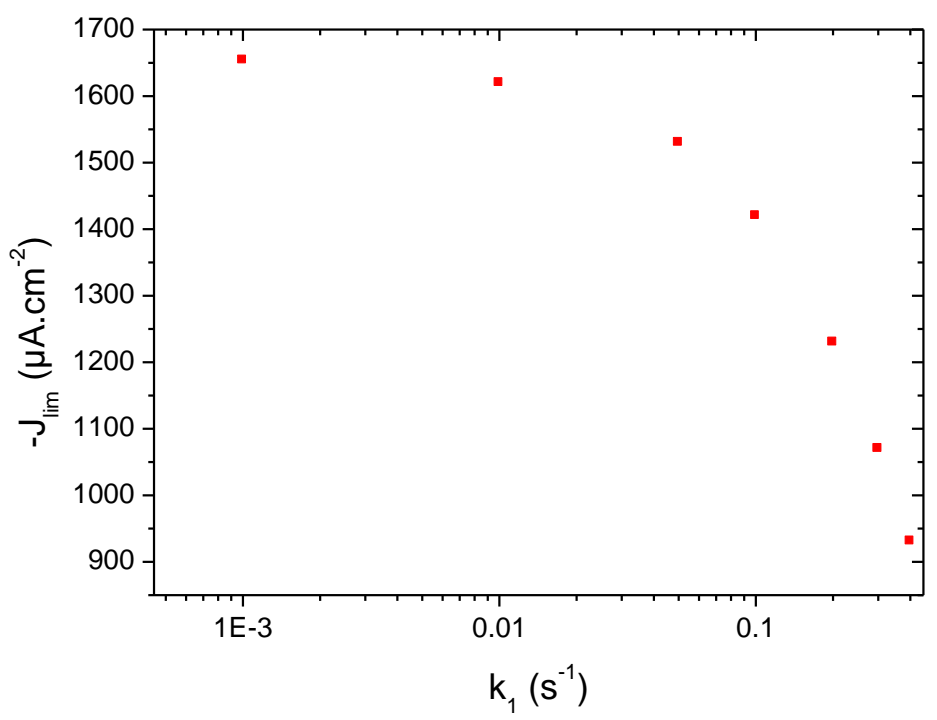

Figure 6 


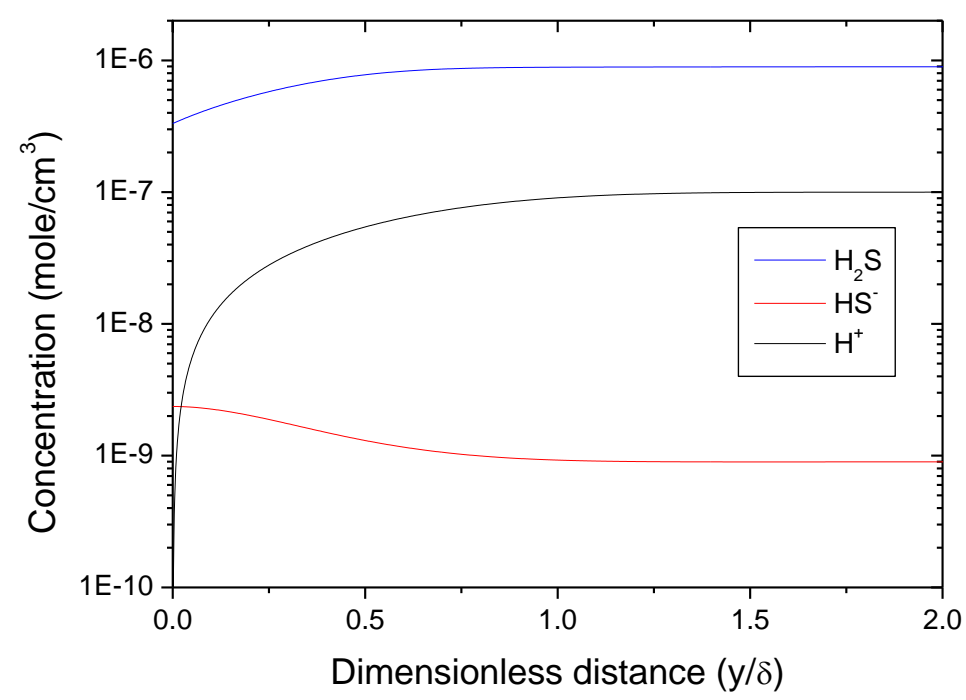

Figure 7 


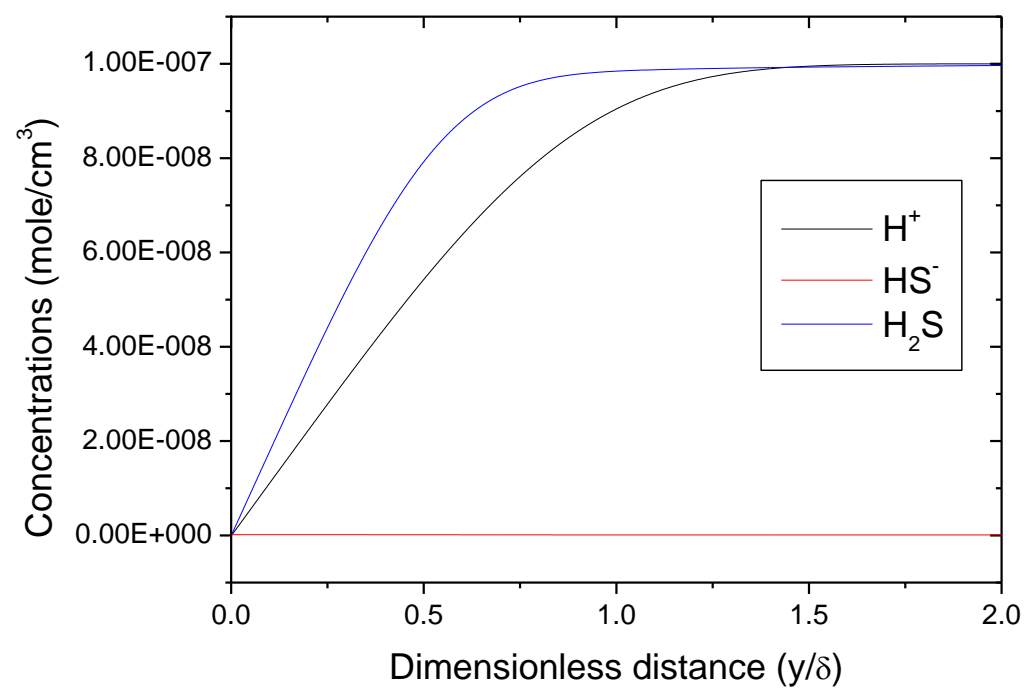

Figure 8 


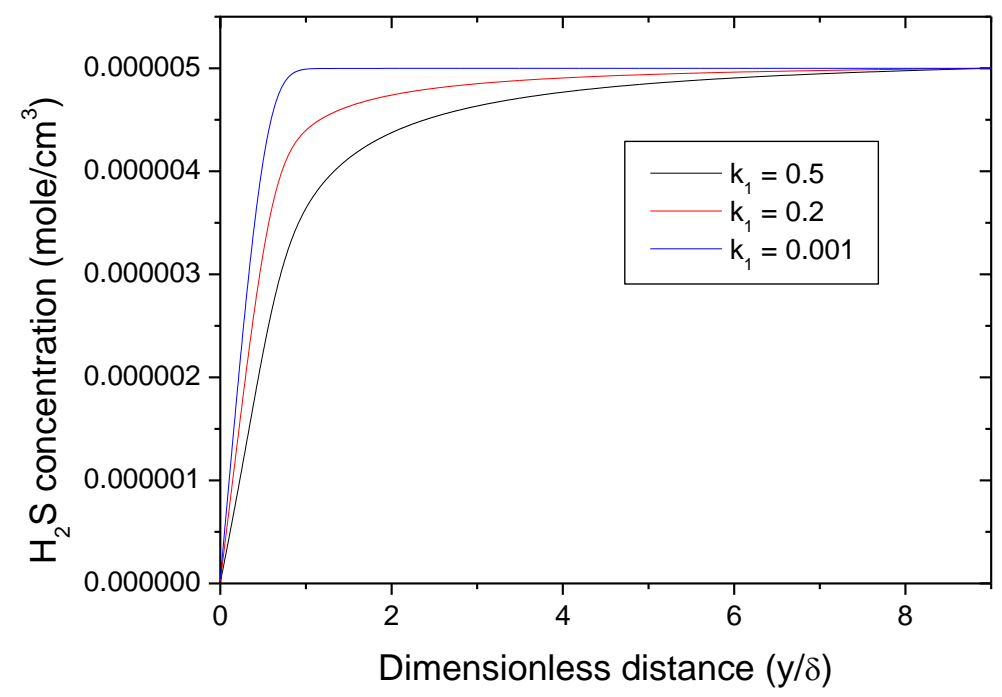

Figure 9 


\begin{tabular}{|l|l|l|}
\hline Constant & Value & References \\
\hline$v$ & $0.01 \mathrm{~cm}^{2} \mathrm{~s}^{-1}$ & \\
\hline$D_{H^{+}}$ & $9.3 \times 10^{-5} \mathrm{~cm}^{2} \mathrm{~s}^{-1}$ & {$[6]$} \\
\hline$D_{H_{2} S}$ & $1.6 \times 10^{-5} \mathrm{~cm}^{2} \mathrm{~s}^{-1}$ & {$[6]$} \\
\hline$D_{H S^{-}}$ & $2 \times 10^{-5} \mathrm{~cm}^{2} \mathrm{~s}^{-1}$ & {$[6]$} \\
\hline$k_{H^{+}}$ & $3 \times 10^{-11} \mathrm{~mol}^{0.5} \mathrm{~cm}^{-0.5} \mathrm{~s}^{-1}$ & {$[1]$} \\
\hline$k_{H_{2} S}$ & $6 \times 10^{-12} \mathrm{~mol}^{0.5} \mathrm{~cm}^{-0.5} \mathrm{~s}^{-1}$ & This study \\
\hline$b_{c, H^{+}}$ & $120 \mathrm{mV}$ & {$[6]$} \\
\hline$b_{c, H_{2} S}$ & $145 \mathrm{mV}$ & {$[1]$} \\
\hline$k_{I}$ & $0.2 \mathrm{~s}^{-1}$ & This study \\
\hline$K_{1}=\frac{k_{1}}{k_{-1}}$ & $10^{-10} \mathrm{~mol} \mathrm{~cm}^{-3}$ & {$[7]$} \\
\hline$K_{2}$ & & \\
\hline
\end{tabular}

Table 1 